\title{
SOME PHYSIOLOGICAL ASPECTS OF RESPIRATORY EMERGENCIES
}

\author{
J. B. L. Howell, B.Sc., Ph.D., M.B., M.R.C.P. \\ Lecturer in Medicine, University of Manchester; Department of Medicine, Manchester Royal Infirmary, \\ Manchester, 13
}

THE term 'respiratory emergency' denotes a state of interference with respiratory exchange to such an extent that life is endangered. While the term is commonly limited to acute disturbances of ventilation in dramatic circumstances (drowning, electrocution, poliomyelitis), in fact a much wider range of conditions can properly be regarded as respiratory emergencies and should be treated as such.

This paper seeks first to classify the various causes of such emergencies on the basis of the physiological processes which have been disturbed. Then follows a description of some of the more important changes in the respiratory gases which result from these disturbances.

\section{Classification of Respiratory Emergencies (i) Ventilation}

Of the four processes involved in pulmonary function, ventilation, distribution, perfusion and diffusion, the one most commonly involved directly in the production of a respiratory emergency is ventilation. The chain of events producing inspiration is initiated by nervous drive originating in the brainstem. This drive is conducted over nervous pathways to the inspiratory muscles, contraction of which generates inspiratory force which is transmitted to the thorax and lungs. This force overcomes the combined elastic and frictional resistances of these structures and inspiration results. Expiration follows passively when the nervous drive wanes. This sequence can be broken at any one or more of these points, and examples of the situations in which this may occur are shown in Table $\mathbf{r}$.

\section{(ii) Ventilation-Perfusion Relationships}

In normal lungs the inspired air is distributed relatively evenly to all alveoli so that the alveolar gas is equally diluted. Similarly, the blood flow around the alveoli is evenly distributed in relation to their ventilation. When the ratio of ventilation to perfusion is the same throughout the lung, respiratory gas exchange is achieved with maxi-

Paper presented to the Meeting of the Harveian Society, October 19, 1960.
TABLE I

Classification of Causes of Respiratory EMERGENCIES

(i) Ventilation: of Examples

(i) Ventilation:

Nervous drive .. Brainstem injury or infection Medullary depressant drugs Electrocution (Emphysema)

Conduction of ner- High cervical cord tranvous drive section

Poliomyelitis

Polyneuritis

Myasthenia gravis

Muscular force .. Acute myositis

(Emphysema)

Transmission of Crush injuries of thorax muscular force' Tension pneumothorax (Emphysema)

Resistances of lungs:

(a) Frictional .

Laryngeal obstruction

Bronchial asthma

Bronchiolitis

(b) Elastic $\quad \ldots \quad$ Atelectasis

Excessive pulmonary resection

(ii) Ventilation-perfusion relationships

Atelectasis

Pulmonary œdema

Bronchial asthma

(Emphysema)

(iii) Diffusion $\quad \ldots \quad$. $\quad$ Pulmonary œdema

mum efficiency. When these relationships are disturbed so that some regions of the lung are over-ventilated in relation to their blood flow, and others are over-perfused in relation to their ventilation, the efficiency of operation of the lungs is impaired. The former disturbance causes a smaller proportion of the tidal ventilation to be effective in achieving gas exchange (increased physiological dead space), and the latter disturbance inevitably results in some inadequately oxygenated blood reaching the systemic circulation (venous admixture).

The importance of disturbed ventilation-perfusion relationships in this context is twofold:

(a) They may in themselves cause respiratory emergencies in conditions such as bronchial asthma and pulmonary œdema; and 
(b) they may so aggravate the effects of a reduction in total ventilation that emergencies may arise out of conditions which otherwise would not be so serious.

The commonest circumstance in which (b) occurs is when obstructive emphysema complicates other causes of hypoventilation. By emphysema is meant an established increase in functional residual capacity (FRC) of the thorax associated with predominantly expiratory obstruction. When patients with this condition develop acute ventilatory failure, they have disturbances of most of the processes of pulmonary function and it is often difficult to apportion the relative importance of each. This is the reason why emphysema appears in several places in the table.

\section{(iii) Diffusion}

The development of pulmonary odema is the commonest way in which a disturbance of the diffusion of gases across the alveolo-capillary membrane causes an emergency. In addition to the increased thickness of the membranes due to the exuded fluid, bubbles form in the airspaces and occlude or partially occlude the airways. This superimposes a severe disturbance of distribution upon that of diffusion. Despite this there is no overall hypoventilation, the arterial $\mathrm{Pco}_{2}$ remaining normal or even being reduced.

\section{Consequences of Hypoventilation}

The behaviour of the carbon dioxide is the key to the understanding of the events which follow ventilatory arrest.

Initially, the mixed venous blood is returning to the lungs with a carbon dioxide tension $\left(\mathrm{PcO}_{2}\right)$ of about $46 \mathrm{~mm} . \mathrm{Hg}$. The alveolar gas is some $6 \mathrm{~mm}$. lower since it is being ventilated with air. Assuming an FRC of 2.5 l., the addition of about $25 \mathrm{ml}$. carbon dioxide to the FRC would abolish this gradient completely. This should occur within a few seconds, after which the blood flowing through the pulmonary capillaries will not lose carbon dioxide, though oxygen will still be taken up. Consequently, the arterial blood returning to the tissues will be loaded with carbon dioxide and will be unable to take up the usual amount from them. The fate of the carbon dioxide accumulating in the tissues is important. Because of the relatively large volume of the body fluids and because of the solubility of carbon dioxide in them, the tissue capacity for carbon dioxide is very large. This results in the tissue $\mathrm{PCO}_{2}$, and therefore that of the mixed venous blood, rising relatively slowly. This rise has been found to be less than $6 \mathrm{~mm}$./minute (Campbell and Howell, 1960), and corresponds to the discharge of about $25 \mathrm{ml}$./minute of carbon

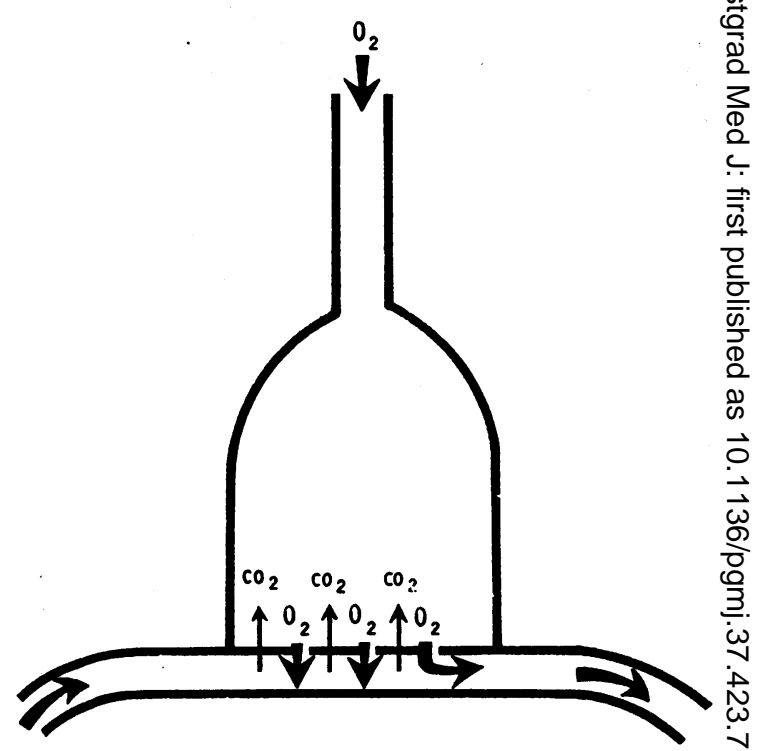

FIG. 1.-To illustrate the mechanism of aventilatory 을 mass flow (AMF). The virtual abolition of the pressure difference for carbon dioxide between $\vec{C}$ capillary and alveolus, results in less carbon dioxide gो being discharged than oxygen taken up. The oxygen is therefore largely replaced by gas drawn in through the trachea.

dioxide into the alveolar gas. The remainder the carbon dioxide produced by the tissues during this time must therefore have been accommodate by the tissue fluids, and in the normal resting state would amount to about $175 \mathrm{ml}$. Over the same period the resting subject would continue to absorb oxygen from the lungs at the normal rate, $\overrightarrow{\vec{P}}$ about $250 \mathrm{ml}$./minute, causing a volume deficit in the lungs of about $225 \mathrm{ml}$./minute. Whether the chest would actually decrease in volume in this way would depend upon whether the airways were patent or not.

If ventilatory arrest occurs with the airways patent there is a mass movement of air into the lungs from the atmosphere enriching the alveolar $\delta$ air and it can be calculated that the oxygen pressure $\left(\mathrm{Po}_{2}\right)$ of the alveolar gas after apnoea of $\frac{\mathrm{O}}{3}$ one minute's duration would be IO-II $\mathrm{mm}$. $\rightarrow$ higher than if this mechanism were not operative. This process has been variously called diffusion respiration (Draper and Whitehead, 1944), apnœic o oxygenation (Nahas and L'Allemand, 1956), but $N$ the term 'aventilatory mass flow' (AMF) (Bart- N lett, Brubach and Specht, I959), though cumbersome, is more accurately descriptive.

If at the onset of the apnœa the subject's airways $\frac{0}{\Phi}$ were connected with a supply of oxygen, the $\stackrel{\infty}{?}$ AMF would consist entirely of oxygen (Fig. I), $\square$ and the $\mathrm{Po}_{2}$ of the alveolar gas would be largely maintained, decreasing only at the rate at which 


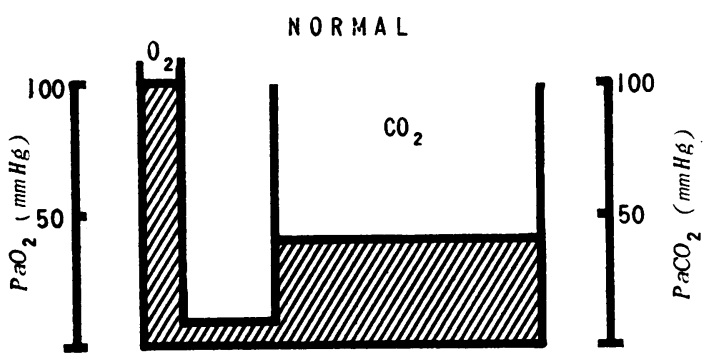

ACUTE VENTILATORY ARREST

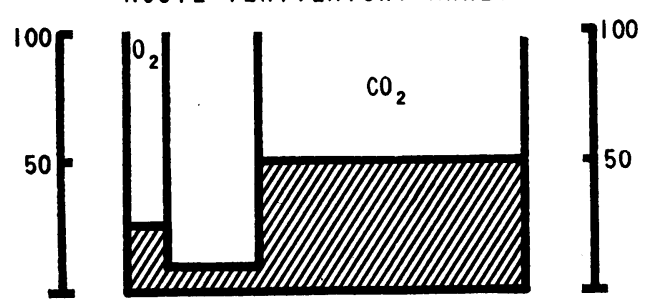

CHRONIC VENTILATORY FAILURE

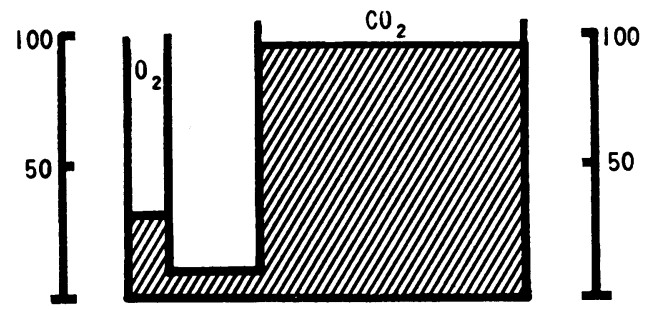

FIG. 2.-Diagrammatic illustration of the body gas stores for oxygen and carbon dioxide. The large capacity of the carbon dioxide store is in contrast to that of the oxygen store.

the $\mathrm{PCO}_{2}$ was rising. This would ensure the delay of lethal levels of anoxia for at least ten minutes. If the subject had been ventilated with oxygen to remove the body's nitrogen stores before the onset of the apnœa, oxygenation could be maintained for longer periods. This is not put forward as a desirable method of treatment of ventilatory failure because it allows an increasing respiratory aci- dosis. However, the mechanism of AMF may well be encountered more frequently in the future in the treatment of ventilatory failure if the use of the hydrogen-ion buffer 'THAM', which can prevent the elevation of the $\mathrm{PCO}_{2}$ (Nahas, Jordan and Ligou, 1959), proves to be capable of therapeutic application.

The rate at which hypoventilation develops affects the changes which occur in the two respiratory gases. When ventilation ceases abruptly, because the store of oxygen in the body is only about I litre (Fahri and Rahn, I955), the $\mathrm{PO}_{2}$ falls rapidly. Lethal levels of anoxia will develop within a few minutes, but the $\mathrm{PCO}_{2}$ will have risen only slightly. In contrast, when hypoventilation develops more slowly, the meagre oxygen stores are supplemented by the ventilation so that the hypoventilation can persist for a longer period, giving the carbon dioxide an opportunity to accumulate in the body tissues and elevate the $\mathrm{PCO}_{2}$ to a greater degree.

These relationships are shown in Fig. 2, where the body gas stores for oxygen and carbon dioxide are shown diagrammatically. The size of the carbon dioxide stores results in a buffering of the tissue $\mathrm{PCO}_{2}$ against changes in ventilation. This becomes of practical importance in the assessment of the ventilatory status of a subject if ventilation is altering rapidly (as, for example, in Cheyne-Stokes respiration or in the apprehensive subject), when the arterial $\mathrm{PcO}_{2}$ might be misleading. In contrast estimation of tissue $\mathrm{PCO}_{2}$ by measurement of the $\mathrm{PCO}_{2}$ in the mixed venous blood would be little affected by such transient changes and would reflect the average alveolar ventilation. Simple methods of estimating mixed venous $\mathrm{PCO}_{2}$ are now available (Collier, 1956; Campbell and Howell, 1960).

This review has been confined to respiratory aspects of the physiological events occurring during respiratory emergencies. There are important cardiovascular aspects which have not been discussed, which are largely concerned with the consequences of the altered intrathoracic pressure relationships produced by artificial ventilation.

\section{REFERENCES}

Bartlett, R. G., Jr., Brubach, H. F., and Specht, H. (1959): Demonstration of Aventilatory Mass Flow During Ventilation and Apnoea in Man, $\mathcal{F}$. Appl. Physiol., 14, 97.

Campbell, E. J. M., and Howell, J. B. L. (1960): Simple Rapid Methods of Estimating Arterial and Mixed Venous $\mathrm{PcO}_{2}$, Brit. med. F., i, 458 .

Collier, C. R. (1956): Determination of Mixed Venous Carbon Dioxide Tensions by Rebreathing, F. Appl. Physiol., 9, 25.

Draper, W. B., and Whitehead, R. W. (1944): Diffusion Respiration in the Dog Anæsthetized by Pentothal Sodium, Anesthesiology, 5, 262.

FAHRI, L. E., and RAHN, H. (1955): Gas Stores of the Body and the Unsteady State, f. Appl. Physiol., 7, 472.

Nahas, G. G., and L'Allemand, H. (1956): Circulation in Dogs After Respiratory Arrest Induced by Curare, Ibid., $8,468$.

- , JoRdan, E. C., and Ligou, J. C. (1959): Effects of a Carbon Dioxide Buffer on Hypercapnia of Apnœic Oxygenation, Amer. F. Physiol., 197, 1308. 